\title{
Original
}

\section{Higher Adiponectin Expression Suppresses Neointimal Hyperplasia by Attenuating the Inflammatory Response Following Acceleration of Endothelialization in Damaged Areas in Adiponectin Transgenic Mice}

\author{
Yasutoshi OMORI ${ }^{1)}$, Hiroshi Suzuki ${ }^{* 2)}$, Kiyomi SAITO ${ }^{3)}$, \\ Makoto ShoJI ${ }^{1)}$, Yoshitaka Iso ${ }^{4)}$, Takaharu NeGORO ${ }^{5}$, \\ Shinji KoBA $^{1)}$, Yasuko NAKANO ${ }^{6)}$ and Youichi KOBAYASHI ${ }^{1)}$
}

\begin{abstract}
Adiponectin prevents inflammation and atherosclerosis, but it is unclear whether overexpression of adiponectin protects the vasculature. The aim of the present study was to determine whether adiponectin overexpression promotes vascular repair after mechanical injury using adiponectin transgenic $(\mathrm{Tg})$ mice. Studies were performed in 7-8-week-old C57/BL6 (wild-type; WT; $\mathrm{n}=50$ ) and adiponectin $\mathrm{Tg}(\mathrm{n}=46)$ mice. A damaged endothelium model was created by inserting a large wire into the femoral artery. Von Willebrand factor-positive cells were observed on the surface of the damaged area from 1 week after wire injury in $\mathrm{Tg}$ mice, and from 2 weeks in WT mice. At 1 week, both $\alpha$-smooth muscle embryonic myosin heavy chain-positive cells and intercellular adhesion molecule-positive cells were observed in the neointima in WT but not $\mathrm{Tg}$ mice. The intima/media ratio was significantly smaller in Tg than WT mice. Adiponectin and tumor necrosis factor (TNF) - $\alpha$ mRNA expression was observed in non-injured Tg and WT mice, but serum and mesenteric adipose tissue adiponectin concentrations were significantly higher in Tg than WT mice. Higher adiponectin and lower TNF- $\alpha$ levels, brought about by adiponectin transgene expression, suppressed neointimal hyperplasia by attenuating the inflammatory response following the acceleration of endothelialization in damaged areas in adiponectin Tg mice.
\end{abstract}

Key words : adiponectin, neointimal hyperplasia, wire injury

\section{Introduction}

Adipose tissue is considered to be an endocrine organ, and previous studies have confirmed that this tissue expresses various secretary proteins ${ }^{1)}$. Of the proteins expressed, the most abundant gene product of adipocytes is adiponectin ${ }^{2-5)}$. Previous studies have shown that

\footnotetext{
1) Department of Medicine, Division of Cardiology, Showa University School of Medicine.

2) Department of Medicine, Division of Cardiology, Showa University Fujigaoka Hospital, 1-30 Fujigaoka, Aoba-ku, Yokohama 227-8501, Japan.

3) Department of Pharmacology, Toxicology and Therapeutics, Division of Physiology and Pathology, Showa University School of Pharmacy.

4) Showa University Research Institute for Sport and Exercise Sciences.

5) Division of Pharmacology, Faculty of Pharmaceutical Sciences, Teikyo Heisei University.

6) Drug treatment Labo., Clinical medicine dept., Yokohama Univ. of Pharmacy.

* To whom corresponding should be addressed.
} 
adiponectin prevents inflammation and the development of atherosclerosis by decreasing the expression of adhesion molecules in endothelial cells and inhibiting the proliferation of vascular smooth muscle cells (VSMCs) ${ }^{6,7)}$. Adiponectin also plays a crucial role in the development of atherosclerosis in patients with type 2 diabetes mellitus and metabolic syndrome ${ }^{8)}$, and low plasma adiponectin concentrations have been reported to be associated with both coronary artery disease and vascular endothelial dysfunction ${ }^{9,10)}$. For example, adiponectin protein is detected in the vasculature when vascular walls are injured ${ }^{11,12)}$. In addition, a strong relationship has been reported between adiponectin and the development of neointimal hyperplasia after vascular injury. Specifically, adiponectin-deficient mice exhibit enhanced proliferation of VSMCs and increased neointimal thickening after vascular mechanical injury ${ }^{13,14)}$. In addition, the adenovirus mediated-expression of Adipoq in adiponectin-knockout mice attenuates the extent of neointimal hyperplasia ${ }^{14)}$. However, these studies were performed under conditions of hypoadiponectinemia, and it remains unclear whether higher adiponectin expression is protective for the process of vascular repair after vascular injury. Therefore, the aims of the present study were to investigate whether higher adiponectin expression promotes vascular repair after mechanical injury using adiponectin transgenic $(\mathrm{Tg})$ mice and to explore the potential mechanisms involved.

\section{Materials and methods}

\section{Animals}

Tg mice $(\mathrm{n}=46)$ expressing mouse adiponectin in all tissues as a result of mouse adiponectincoding region knock-in (C57B/L6 background ${ }^{15)}$ were maintained in the animal facility of Showa University. Adult Tg male mice, 7-8 weeks of age and weighing 25-30 g, were used in the experiments. Adult wild-type (WT) male mice $(\mathrm{C} 57 \mathrm{~B} / \mathrm{L} 6 \mathrm{~J} ; \mathrm{n}=50 ; 7-8$ weeks old, 25-30 g) were used as controls. For all surgical procedures, mice were anesthetized by intraperitoneal injection of $50 \mathrm{mg} / \mathrm{kg}$ pentobarbital diluted in $0.9 \%$ sodium chloride solution. The present study conformed to the "Guidelines for the Care and Use of Laboratory Animals published by the US National Institutes of Health” (NIH publication No.86-23, revised 1985). The experimental protocol was approved by the Animal Care and Use Committee of Showa University.

\section{Mouse femoral injury model}

The surgery was performed under a dissecting microscope (SMZ-800; Nikon, Tokyo, Japan). Transluminal mechanical injury of the femoral artery was induced by inserting a large wire (0.38 mm diameter; COOK, Bloomington, IN, USA) into the artery, as described previously ${ }^{16,17)}$. This method induces endothelial denudation, massive apoptosis of the media, and severe neointimal hyperplasia. The mice were then killed by pentobarbital overdose, injected intraperitoneally, at different time points: 3 days $(\mathrm{Tg}: \mathrm{n}=10 ; \mathrm{WT}: \mathrm{n}=8), 1$ week $(\mathrm{Tg}: \mathrm{n}=9$; WT: $\mathrm{n}=14), 2$ weeks (Tg: $n=15 ; \mathrm{WT}: \mathrm{n}=14)$, and 4 weeks $(\mathrm{Tg}: \mathrm{n}=12 ; \mathrm{WT}: \mathrm{n}=14)$. Mice in which wire injury was not induced ( $\mathrm{Tg}: \mathrm{n}=6$; WT: $\mathrm{n}=6$ ) were used as uninjured controls. After blood samples had been obtained from the right ventricle, mice were perfused with $0.9 \% \mathrm{NaCl}$ solution. The femoral artery was carefully excised, fixed in $4 \%$ paraformaldehyde overnight at $4^{\circ} \mathrm{C}$, and embedded in 
Table 1. Sources and specificities of all primary antibodies used in the present study

\begin{tabular}{llllr}
\hline \multicolumn{1}{c}{ Antibody } & Source & \multicolumn{1}{c}{ Cell identified } & \multicolumn{1}{c}{ Manufacturer } & Working dilution \\
\hline Adiponectin & Goat & Adiponectin-presenting cell & R\&D Systems (Minneapolis, MN, USA) & $1: 500$ \\
vWF & Goat & Endothelial cell & Santa Cruz Biotechnology (Santa Cruz, CA, USA) & $1: 200$ \\
ICAM-1 & Goat & ICAM-1-presenting cell & Santa Cruz Biotechnology & $1: 100$ \\
$\alpha$-SMemb & Mouse & De-differentiated VSMC & Yamasa (Tokyo, Japan) & $1: 300$ \\
$\alpha$-SMA & Mouse & VSMC & Sigma (St. Louis, MO, USA) & $1: 200$ \\
\hline
\end{tabular}

vWF, von Willebrand factor; ICAM-1, intercellular adhesion molecule-1; $\alpha$-SMemb, embryonic smooth muscle myosin heavy chain; $\alpha$-SMA, $\alpha$-smooth muscle actin; VSMC, vascular smooth muscle cell.

paraffin. The paraffin-embedded fixed arteries were divided into several $100-\mu \mathrm{m}$ long blocks, and thin cross-sections $(5 \mu \mathrm{m})$ were then cut from each block. The thin cross-sections were subsequently stained with hematoxylin and eosin, elastic Van Gieson, or Azan-Mallory stains for histopathological evaluation. Furthermore, five additional different thin cross-sections from each elastic Van Gieson-stained block were used for morphometric analyses.

\section{Immunohistochemistry}

Immunohistochemical analyses were performed to determine the localization of various proteins in the femoral arteries. At the time of death, each mouse was perfused with $0.9 \% \mathrm{NaCl}$ solution, followed by per- fusion fixation with $4 \%$ paraformaldehyde in phosphate-buffered saline (PBS) ( $\mathrm{pH}$ 7.4). The femoral artery was carefully excised, fixed in $4 \%$ paraformaldehyde overnight at $4^{\circ} \mathrm{C}$ and embedded in paraffin. Mouse femoral artery was embedded in paraffin, cut into the thin cross-sections for immunohistochemistry, deparaffinized in xylene, dehydrated in phosphatebuffered saline (PBS; pH 7.4), and incubated with $0.3 \% \mathrm{H}_{2} \mathrm{O}_{2}$ in methanol for $10 \mathrm{~min}$ to quench endogenous peroxidase activity. After a further $15 \mathrm{~min}$ of rinsing with PBS and 10 min incubation with diluted normal serum, sections were incubated with primary antibodies at room temperature for $60 \mathrm{~min}$. The sources and specificity of all primary antibodies used in the present study are summarized in Table 1. Bound antibodies were visualized using the avidin-biotin complex technique, after which the sections were counterstained with hematoxylin.

\section{Morphometric analysis}

Lesions were analyzed morphometrically as described previously ${ }^{16,18)}$. Briefly, the lumen and internal and external elastic laminae in each thin cross-section were traced using an image analysis software program (Image-Pro Plus version 4.5; Media Cybernetics, Sarasota, FL, USA). The intimal area was determined by subtracting the area of the lumen from the area enclosed by the internal elastic lamina. The medial area was determined by subtracting the area enclosed by the internal elastic lamina from the area enclosed by the external elastic lamina. The intima/media ratio was averaged for each artery. 
Table 2. Probes used in real-time polymerase chain reaction

\begin{tabular}{llll}
\hline Gene symbol & \multicolumn{1}{c}{ Gene name } & \multicolumn{1}{c}{ Assay ID } & NCBI gene reference \\
\hline Actb & $\beta$-Actin & 4352933E & NM_007393.3 \\
& & (Thermo Fisher Scientific, Waltham, MA, USA) & \\
Adipoq & Adiponectin & $\begin{array}{l}\text { Mm00456425_m1 } \\
\text { (Thermo Fisher Scientific, Waltham, MA, USA) }\end{array}$ & NM_009605.4 \\
Tnf & Tumor necrosis factor- $\alpha$ & $\begin{array}{l}\text { Mm00443258_m1 } \\
\text { (Thermo Fisher Scientific, Waltham, MA, USA) }\end{array}$ & NM_013693.2 \\
& &
\end{tabular}

Serum and adipose tissue concentrations of adiponectin and tumor necrosis factor- $\alpha$

Concentrations of adiponectin and tumor necrosis factor (TNF)- $\alpha$ were determined by ELISA. Serum and mesenteric adipose tissue samples were frozen at below $-80^{\circ} \mathrm{C}$ immediately after sampling and thawed just before homogenization. Samples were homogenized with $0.9 \% \mathrm{NaCl}$ solution and sonication buffer ( $\mathrm{pH}$ 7.2; composition: $20 \mathrm{mM}$ HEPES buffer [Sigma, St. Louis, MO, USA], 2 mM EDTA [DOJINDO, Kumamoto, Japan], and 2\% Triton X-100 [Sigma]), after which adiponectin and TNF- $\alpha$ concentrations were determined using commercially available ELISA kits (Mouse Adiponectin ELISA Kit [R\&D Systems, Minneapolis, MN, USA] and Mouse TNF- $\alpha$ ELISA kit [Biosource, Carlsbad, CA, USA], respectively).

\section{Reverse transcription-polymerase chain reaction}

At the time of death, mice were perfused with $0.9 \% \mathrm{NaCl}$ solution, and the femoral artery, aorta, and mesenteric adipose tissue were quickly excised. Samples were preserved in RNAzol reagent (Tri-Reagent; Molecular Research Center, Cincinnati, OH, USA) and used to prepare total RNA and first-strand cDNA. mRNA expression was quantified using real-time reverse transcription-polymerase chain reaction (RT-PCR) with the Taq Man First Universal PCR Master Mix (Applied Biosystems, Foster City, CA, USA) using a high-capacity cDNA Reverse Transcription kit (Step One Plus Real Time PCR system; Applied Biosystems). All the oligonucleotide primers and fluorogenic probes for Taqman real-time PCR were prepared by Applied Biosystems (Table 2). The PCR conditions consisted of 40 cycles of first denaturation cycle for $2 \mathrm{~min}$ at $95^{\circ} \mathrm{C}$, second denaturation for $95^{\circ} \mathrm{C}$, and annealing and extension for $20 \mathrm{sec}$ at $60^{\circ} \mathrm{C}$.

\section{Statistical analyses}

Unpaired Student's $t$-test was used for comparisons of mean intima/media ratios between groups. Adiponectin and TNF- $\alpha$ concentrations were compared using repeated-measures analysis of variance followed by Scheffé's multiple comparison test. Data are presented as the mean \pm SEM. For the two-tailed test, $P<0.05$ was considered significant.

\section{Results}

Histological and morphometric analyses

The insertion of the large wire into the femoral artery completely denuded the endothelium 
and markedly enlarged the lumen. This procedure induced neointimal hyperplasia in the WT group, whereas this response was suppressed in the Tg group (Fig. 1). As shown in Fig. 1A, only a small number of cells had migrated into the injured areas in the $\mathrm{Tg}$ group, and the luminal areas in the Tg group were larger than those observed in the WT group 1 week after wire injury. In the WT group, large cells with a large nucleus had migrated into the injured areas by 1 week after wire injury, narrowing the luminal area (Fig. 1B). Two weeks after wire injury, abnormal neointimal hyperplasia was detected in the injured vessels of the WT group (Fig. 1D). In contrast, at the same time point the neointimal areas in the injured vessels of the $\mathrm{Tg}$ were small (Fig. 1C). Four weeks after wire injury, the neointimal areas in the $\mathrm{Tg}$ group (Fig. 1E) were thinner than those in the WT group (Fig. 1F). In the WT group, the neointima was markedly thickened, the luminal areas were narrowed, and the media was almost intact (Fig. 1F). Figure $1 \mathrm{G}$ shows the differences in the intima/media ratios between the Tg and WT groups at 1 week $(\mathrm{Tg}: \mathrm{n}=9$; WT: $\mathrm{n}=15), 2$ weeks $(\mathrm{Tg}: \mathrm{n}=12$; WT: $\mathrm{n}=12)$, and 4 weeks $(\mathrm{Tg}: \mathrm{n}=6$; WT: $\mathrm{n}=$ 6) after wire injury. The neointimal areas were significantly smaller in the $\mathrm{Tg}$ group than in the WT group at each time point $(0.75 \pm 0.06$ vs $1.18 \pm 0.09$, respectively, at 1 week; $0.37 \pm 0.02$ vs $1.66 \pm 0.21$, respectively, at 2 weeks; and $1.35 \pm 0.27$ vs $1.94 \pm 0.50$, respectively, at 4 weeks; $P$ $<0.05$ for all).

\section{Immunohistochemical analysis}

Among the endothelial cells obtained from the uninjured control mice, adiponectin-positive cells were detected in both the Tg and WT groups (Fig. 2A). In the wire injury groups, 1 week after injury adiponectin-positive cells had covered the damaged areas in the Tg group (Fig. 2Ba) and these cells were also positive for von Willebrand Factor (vWF; Fig. 2Bc). In contrast, no adiponectin- or vWF-positive cells were detected in the WT group (Fig. 2Bb, d). Endothelial cells from mice in the WT group were positive for intercellular adhesion molecule-1 (ICAM-1; Fig. 2Bf), but few ICAM-1-positive reactions were observed in the Tg group (Fig. 2Be). This suggests that the inflammatory reactions were persistent in the WT group, but not in the Tg group. In addition, the large cells with a large nucleus in the WT group were positive for embryonic $\alpha$ smooth muscle myosin heavy chain $(\alpha-\mathrm{SMemb})$, indicating that these cells were immature VSMCs (Fig. 2Bh). In contrast, cells in the damaged areas in the Tg group did not react with the anti- $\alpha$-SMemb antibody (Fig. $2 \mathrm{Bg}$ ). Two weeks after wire injury, the endothelial cells in both the Tg (Fig. 2Ca, c) and WT (Fig. 2Cb, d) groups were positive for adiponectin and vWF.

\section{Tissue and serum concentrations of adiponectin and TNF- $\alpha$}

Fig. 3 shows adiponectin and TNF- $\alpha$ concentrations in mesenteric adipose tissues (Fig. 3A, C) and serum (Fig. 3B, D) from the Tg and WT groups. Before wire injury, adiponectin concentrations in the mesenteric adipose tissue were significantly higher in the Tg than WT group (30.0 \pm 7.4 vs $17.7 \pm 0.8 \mu \mathrm{g} / \mathrm{g}$, respectively; $P<0.05$; Fig. 3A) ; similarly, serum adiponectin concentrations were higher in the Tg than WT group $(4.7 \pm 0.1$ vs $4.3 \pm 0.1 \mu \mathrm{g} / \mathrm{ml} ; P<0.05$; Fig. 3B). After wire injury, adiponectin levels in mesenteric adipose tissue in both groups were significantly lower 

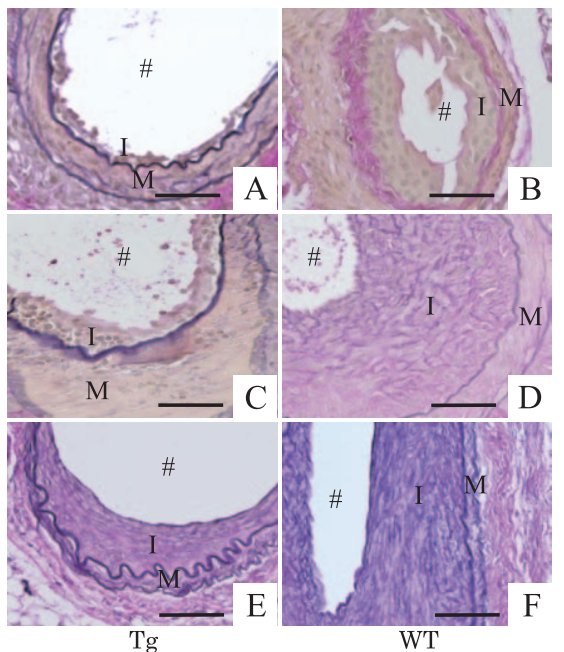

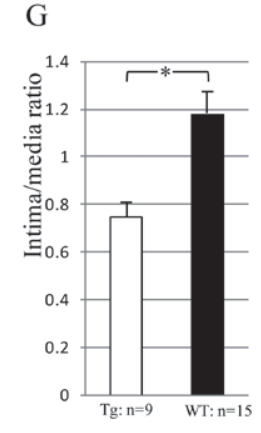

1-week

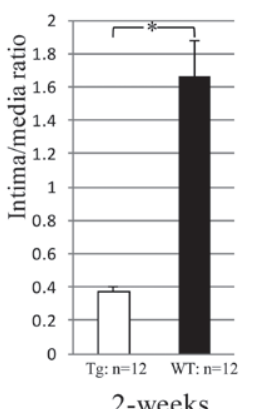

2-weeks

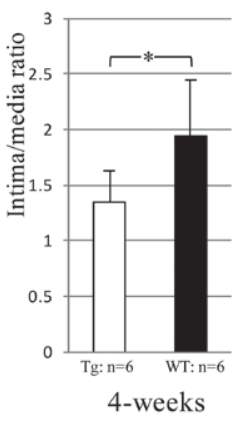

Fig. 1. Elastic Van Gieson staining for adiponectin in (A, C, E) transgenic ( Tg) and (B, D, F) wild-type (WT) mice 1 week (A, B), 2 weeks (C, D) and 4 weeks (E, F) after wire injury. The luminal areas in the Tg mice were larger than those observed in WT mice 1 week after wire injury (A). In the WT mice 1 week after wire injury, the luminal areas were narrowed (B). Two weeks after wire injury, abnormal neointimal hyperplasia was detected in the injured vessels of WT mice (D). In contrast, the neointimal areas were small in the injured vessels of $\mathrm{Tg}$ mice at the same time point (D). Four weeks after wire injury, the neointimal areas in $\mathrm{Tg}$ mice (E) were thinner than those in WT mice (F). In the WT mice, the neointima was markedly thickened, the luminal areas were narrowed, and the media was almost intact $(\mathrm{F})$. Bars, $50 \mu \mathrm{m}$. (G) The intima/media ratios of the injured femoral arteries calculated 1,2 and 4 weeks after vascular injury were significantly higher in WT than Tg mice. Data are the mean \pm SEM ( 1 week, $\mathrm{n}=9$ and 15 in Tg and WT mice, respectively; 2 weeks, $\mathrm{n}=12$ in both groups; 4 weeks, $\mathrm{n}=6$ in both groups). ${ }^{*} P<0.05$.

A

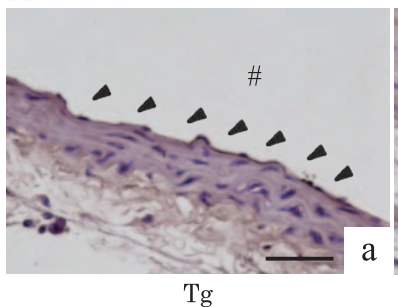

c

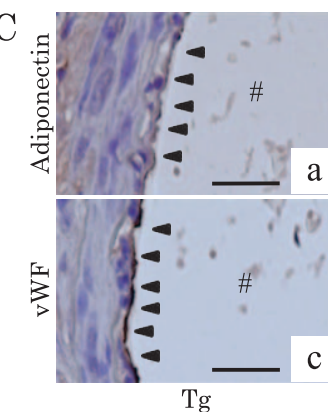

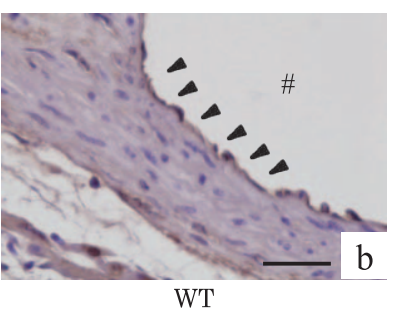

WT

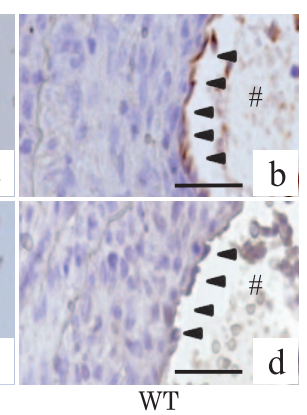

B
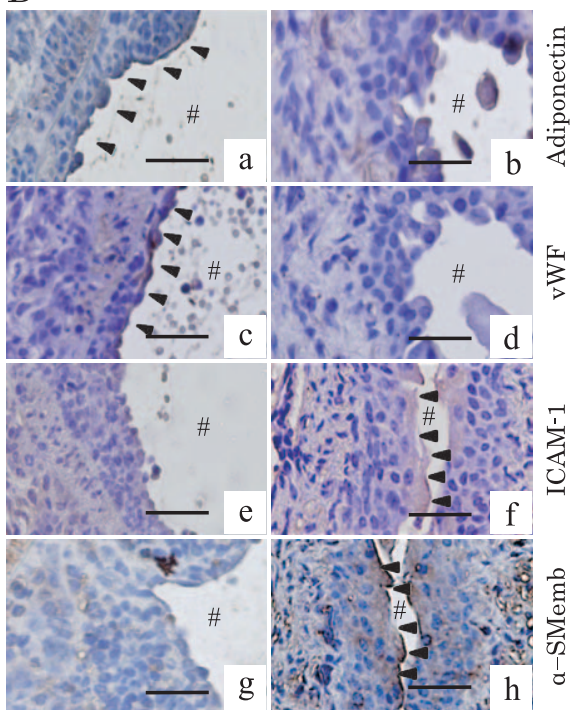

$\mathrm{Tg}$

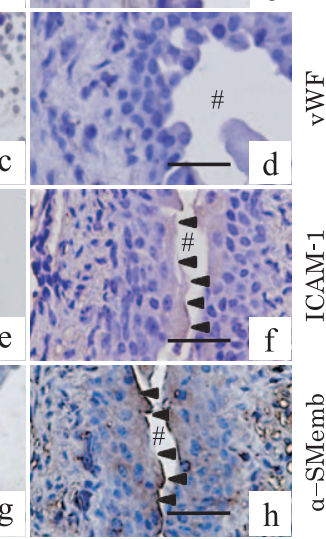

WT

Fig. 2. Immunohistochemical analyses were performed on blood vessels from transgenic (Tg) and wild-type (WT) mice. (A) Adiponectin-positive cells were identified in aortas from $\mathrm{Tg}$ (a) and WT (b) mice that were not subjected to wire injury. (B) One week after wire injury, cells positive for adiponectin, von Willebrand Factor (vWF), intercellular adhesion molecule-1 (ICAM-1), and embryonic $\alpha$-smooth muscle myosin heavy chain ( $\alpha$-SMemb) were seen in the damaged areas in $\mathrm{Tg}(\mathrm{a}, \mathrm{c}, \mathrm{e}, \mathrm{g})$ and $\mathrm{WT}(\mathrm{b}, \mathrm{d}, \mathrm{f}, \mathrm{h})$ mice. (C) Two weeks after wire injury, both adiponectin- and vWF-positive cells were evident in the damaged areas in $\mathrm{Tg}(\mathrm{a}, \mathrm{c})$ and WT (b, d) mice. Bars, $50 \mu \mathrm{m}$. \#, lumen. 
at each time point compared with the uninjured control groups $(P<0.05)$. However, adiponectin concentrations in mesenteric adipose tissue remained significantly higher in the $\mathrm{Tg}$ than WT group at all time points $(P<0.05$; Fig. 3A). Serum adiponectin concentrations were significantly higher in the $\mathrm{Tg}$ group 1 week after wire injury compared with uninjured mice, whereas there was no change in serum adiponectin concentrations in the WT group until 2 weeks after wire injury. The difference in the serum adiponectin levels between the two groups remained significant until 4 weeks (Fig. 3B).

Meanwhile, in uninjured mice, TNF- $\alpha$ concentrations were significantly higher in the WT than $\mathrm{Tg}$ group in both mesenteric adipose tissue $(11.4 \pm 0.1$ vs $7.3 \pm 1.5 \mathrm{ng} / \mathrm{g}$, respectively; $P<0.05$; Fig. 3C) and serum $(530.7 \pm 38.3$ vs $443.7 \pm 10.5 \mathrm{pg} / \mathrm{ml}$, respectively; $P<0.05$; Fig. 3D). TNF$\alpha$ concentrations in the mesenteric adipose tissue were significantly higher in the WT than $\mathrm{Tg}$ group at each time point (Fig. 3C). In mesenteric adipose tissue, TNF- $\alpha$ concentrations in the WT group increased on Day 3, but decreased thereafter. In contrast, in the Tg group, no differences in TNF- $\alpha$ concentrations were noted between the uninjured control mice and values obtained on Day 3. One week after injury, TNF- $\alpha$ concentrations in mesenteric adipose tissue were significantly lower in both the Tg and WT groups compared with concentrations in uninjured control mice $(P<0.05)$. The time course of changes in serum TNF- $\alpha$ concentrations was similar between the Tg and WT groups. Furthermore, serum TNF- $\alpha$ concentrations were significantly higher in the WT than Tg group at each time point.

\section{Expression of adiponectin and TNF- $\alpha$ mRNA}

Expression of adiponectin mRNA in the heart was significantly higher in $\mathrm{Tg}$ than WT mice $(P<0.05$; Fig. 4A). In contrast, TNF- $\alpha$ mRNA expression in the heart and liver was significantly higher in WT than in Tg mice $(P<0.05$; Fig. 4B).

\section{Discussion}

The role of adiponectin in vascular injury has been investigated using experimental models ${ }^{19,20)}$. Adiponectin-knockout mice develop marked neointimal hyperplasia after vascular injury ${ }^{14,19)}$, and adiponectin deficiency has been reported to induce the progression of neointimal hyperplasia in a mouse cuff-injury model ${ }^{6}$. Furthermore, adenovirus-mediated overexpression of full-length $A d i$ poq results in a marked alleviation of atherosclerotic lesions in apolipoprotein E-deficient mice ${ }^{20)}$. These findings suggest that sufficient expression of adiponectin is required to repair the vascular wall following mechanical injury.

In the present study, using an adiponectin-coding region knock-in strain of $\mathrm{Tg}$ mice that theoretically express adiponectin essentially in all tissues, we clearly demonstrated that slightly higher adiponectin expression, not overexpression, promotes vascular repair after mechanical injury, with the prevention of neointimal hyperplasia after wire injury in the Tg mice (Fig. 1). Furthermore, adiponectin- and vWF-positive cells were observed in the injured areas in the Tg group 1 week after injury (Fig. 2Ba, c), with these cells rarely seen in the WT group (Fig. 2Bb, d). Conversely, cells positive for ICAM-1 and $\alpha$-SMemb were more frequently detected in the WT 

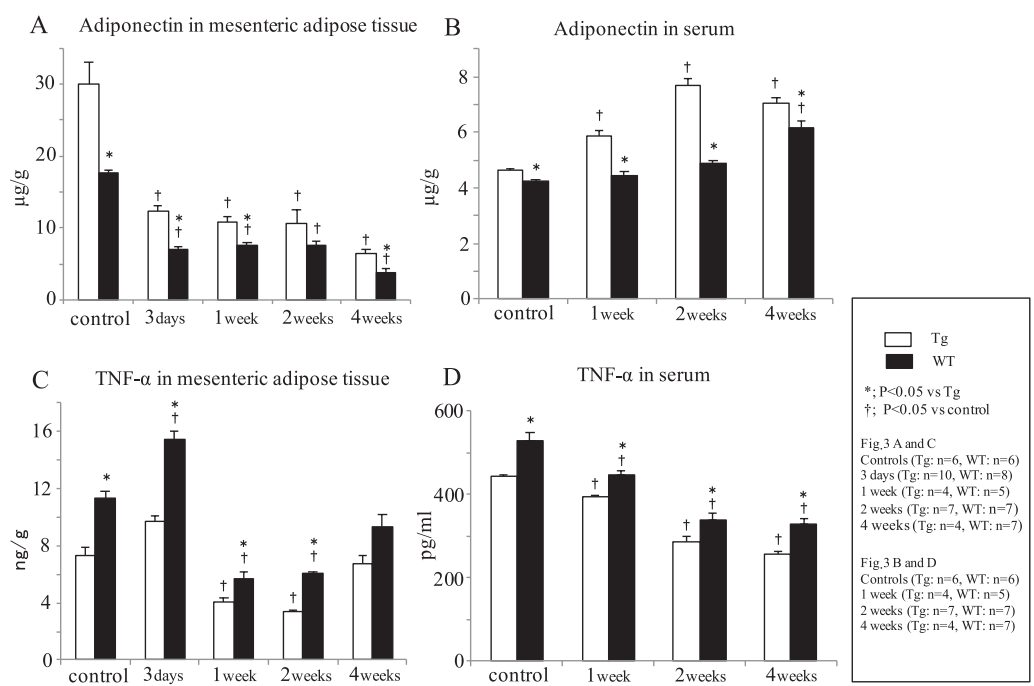

Fig. 3. (A, B) Adiponectin and (C, D) tumor necrosis factor (TNF)$\alpha$ concentrations in mesenteric adipose tissue $(\mathrm{A}, \mathrm{C})$ and serum (B, D) from transgenic (Tg) and wild-type (WT) mice with and without (control) wire injury. Data are the mean \pm SEM. ${ }^{\dagger} P<0.05$ compared with control; ${ }^{*} P<0.05$ compared with the $\mathrm{Tg}$ group at the same time point.

A

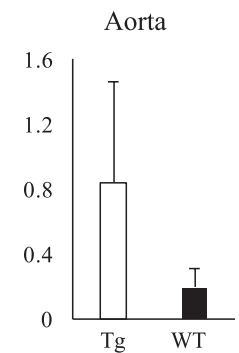

B

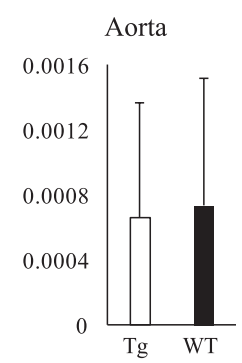

mRNA expression of Adiponectin

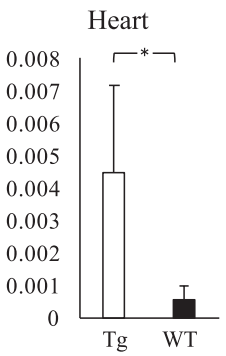

mRNA expression of TNF- $\alpha$

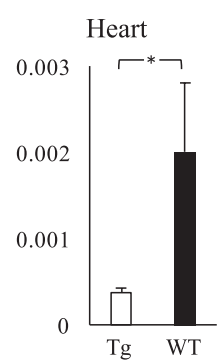

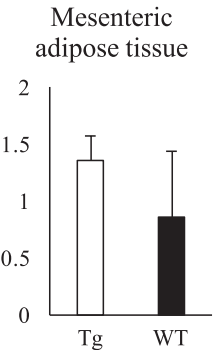

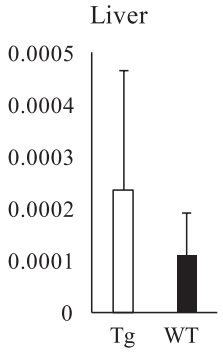

$* ; \mathrm{P}<0.05 \mathrm{vsTg}$

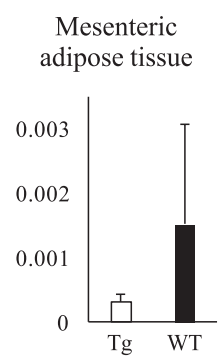

Fig. 4. Expression of (A) adiponectin and (B) tumor necrosis factor (TNF) $-\alpha$ in the aorta, heart, mesenteric adipose tissue, and liver of transgenic (Tg) and wild-type (WT) mice. Adiponectin and TNF- $\alpha$ mRNA expression was normalized against that of $\beta$-actin, used as an internal control. Data are the mean \pm SEM (aorta, $\mathrm{n}=2$ and 5 for $\mathrm{Tg}$ and WT mice, respectively; heart, mesenteric adipose tissue, and liver, $\mathrm{n}=4$ and 5 for $\mathrm{Tg}$ and $\mathrm{WT}$ mice, respectively). ${ }^{*} P<$ 0.05 . 
group (Fig. 2Bf, h) than in the Tg group (Fig. 2Be, g). We think that these $\alpha$-SMemb-positive cells that had migrated into the damaged area in the WT group were immature smooth muscle cells that were also positive for ICAM-1 ${ }^{21)}$. However, 2 weeks after wire injury, adiponectinand vWF-positive cells could be detected in both groups (Fig. 2C). These observations indicate prolonged inflammation in the WT group, whereas in the Tg group the inflammatory reaction in the damaged area was decreased at 1 week after wire injury.

Adiponectin concentrations in mesenteric adipose tissues from both groups were significantly decreased after injury, although concentrations were significantly higher in the Tg than WT group at each time point (Fig. 3A). Meanwhile, serum adiponectin concentrations were increased in the $\mathrm{Tg}$ group from the early phase after injury, with higher values than in the WT group (Fig. 3B). Both serum and mesenteric adipose tissue concentrations of adiponectin were significantly higher in the Tg than WT group (Fig. 3A, B), whereas concentrations of TNF- $\alpha$ in the serum and mesenteric adipose tissues were lower in the Tg than WT group (Fig. 3C, D). As shown in Fig. 3, after wire injury, TNF- $\alpha$ concentrations in adipose tissue increased transiently on Day 3 , and then decreased. Conversely, adiponectin protein was decreased in adipose tissue, but was increased in the serum. The transient decrease in serum adiponectin was induced by tissue damage, whereby adiponectin binds to the damaged area ${ }^{22)}$ and, after wound repair, serum adiponectin concentrations rebound ${ }^{23)}$.

Acute adiponectin expression could be induced by inflammation in only $3 \mathrm{~h}$, as reported previously ${ }^{24,25)}$, and chronic inflammation induces constant high adiponectin expression and high serum concentrations ${ }^{26,27)}$. Because adiponectin expression could be detected in endothelial cells of the WT group (Fig. 2A) and adiponectin protein has been reported in endothelial cells of the aortic intima in the steady state ${ }^{28)}$, we analyzed adiponectin and TNF- $\alpha$ mRNA expression in the present study using RT-PCR. Adiponectin mRNA expression was detected in the aorta, mesenteric adipose tissue, and the liver. Expression of adiponectin mRNA in the heart was significantly higher in the Tg than WT group $(P<0.05$; Fig. 4A). In contrast, TNF- $\alpha$ mRNA expression in the heart and liver was significantly higher in the WT than $\mathrm{Tg}$ group $(P<0.05$; Fig. 4B). Furthermore, in mesenteric adipose tissue, adiponectin concentrations were significantly higher in the Tg than WT group. Conversely, TNF- $\alpha$ concentrations were significantly lower in the Tg than WT group at steady state. Because adiponectin accumulates in inflamed tissues in order to promote healing of damaged areas through its anti-inflammatory actions, we suggest that the constantly higher expression of adiponectin in some tissues in the $\mathrm{Tg}$ group, and the resulting higher serum adiponectin concentrations, resulted in low TNF- $\alpha$ mRNA and protein levels. TNF- $\alpha$ induces the migration and proliferation of immature smooth muscle cells through extracellular signal-regulated kinase (ERK) $1 / 2$ signaling. Adiponectin inhibits TNF- $\alpha$ production and inflammation and enhances the migration and differentiation of endothelial progenitor cells via phosphatidylinositol 3-kinase (PI3K)-Akt signaling ${ }^{29,30)}$. The $\mathrm{Tg}$ mice used in the present study express adiponectin essentially in all tissues, which is the biggest difference between the $\mathrm{Tg}$ and WT groups in the present study. The higher level of adiponectin expression in Tg than in WT mice made the inflammatory reaction end earlier in the former. In addition, the termination of 
inflammation may result in earlier endothelial repair, thus suppressing neointimal hyperplasia.

\section{Conclusion}

A high level of adiponectin and low TNF- $\alpha$ concentrations, brought about as a result of the higher adiponectin expression, suppress neointimal hyperplasia by attenuating the inflammatory response following the acceleration of endothelialization in damaged areas in adiponectin $\mathrm{Tg}$ mice.

\section{Acknowledgements}

The authors thank Mr. Ryuji Sato and Drs. Teruko Soda and Takatoshi Sato for their technical assistance.

This work was supported in part by the Japanese Ministry of Education, Culture, Sports, Science, and Technology [Grant-in-Aid for Scientific Research (C), 23590474 and 26460494], [Private University High Technology Research Center Project matching fund subsidy from MEXT].

\section{Conflict of interest disclosure}

The authors have declared no conflict of interest.

\section{References}

1) Tilg H, Moschen AR. Adipocytokines: mediators linking adipose tissue, inflammation and immunity. Nat Rev Immunol. 2006;6:772-783.

2) Nakano Y, Tobe T, Choi-Miura NH, et al. Isolation and characterization of GBP28, a novel gelatin-binding protein purified from human plasma. J Biochem. 1996;120:803-812.

3) Maeda K, Okubo K, Shimomura I, et al. cDNA cloning and expression of a novel adipose specific collagen-like factor, apM1 (AdiPoseMost abundant Gene transcript 1). Biochem Biophys Res Commun. 1996;221:286-289.

4) Scherer PE, Williams S, Fogliano M, et al. A novel serum protein similar to C1q, produced exclusively in adipocytes. J Biol Chem. 1995;270:26746-26749.

5) $\mathrm{Hu}$ E. Liang P, Spiegelman BM. AdipoQ is a novel adipose-specific gene dysregulated in obesity. J Biol Chem. 1996;271:10697-10703.

6) Ouchi N, Kihara S, Arita Y, et al. Novel modulator for endothelial adhesion molecules: adipocyte-derived plasma protein adiponectin. Circulation. 1999;100:2473-2476.

7) Arita Y, Kihara S, Ouchi N, et al. Adipocyte-derived plasma protein adiponectin acts as a platelet derived growth factor-BB-binding protein and regulates growth factor-induced common postreceptor signal in vascular smooth muscle cell. Circulation. 2002;105:2893-2898.

8) Hotta K, Funahashi T, Arita Y, et al. Plasma concentrations of a novel, adipose-specific protein, adiponectin, in type 2 diabetic patients. Arterioscler Thromb Vasc Biol. 2000;20:1595-1599.

9) Kumada M, Kihara S, Sumitsuji S, et al. Association of hypoadiponectinemia with coronary artery disease in men. Arterioscler Thromb Vasc Biol. 2003;23:85-89.

10) Ouchi N, Ohishi M, KiharaS, et al. Association of hypoadiponectinemia with impaired vasoreactivity. Hypertension. 2003;42:231-234.

11) Okamoto Y, Arita Y, Nishida M, et al. An adipocyte-derived plasma protein, adiponectin, adheres to injured vascular walls. Horm Metab Res. 2000;32:47-50.

12) Ouchi N, Kihara S, Arita Y, et al. Adipocyte-derived plasma protein, adiponectin, suppresses lipid accumulation and class A scavenger receptor expression in human monocyte-derived macrophages. Circulation. 2001;103:1057-1063. 
13) Kubota N, Terauchi Y, Yamauchi T, et al. Disruption of adiponectin causes insulin resistance and neointimal formation. J Biol Chem. 2002;277:25863-25866.

14) Matsuda M, Shimomura I, Sata M, et al. Role of adiponectin in preventing vascular stenosis. The missing link of adipo-vascular axis. J Biol Chem. 2002;277:37487-37491.

15) Saito K, Arata S, Hosono $\mathrm{T}$, et al. Adiponectin plays an important role in efficient energy usage under energy shortage. Biochim Biophys Acta. 2006;1761:709-716.

16) Koglin J, Glysing-Jensen $\mathrm{T}$, Raisanen-Sokolowski A, et al. Immune sources of transforming growth factor-beta1 reduce transplant arteriosclerosis: insight derived from a knockout mouse model. Circ Res. 1998;83:652-660.

17) Sata M, Maejima Y, Adachi F, et al. A mouse model of vascular injury that induces rapid onset of medial cell apoptosis followed by reproducible neointimal hyperplasia. J Mol Cell Cardiol. 2000;32:2097-2104.

18) Shoji M, Sata M, Fukuda D, et al. Temporal and spatial characterization of cellular constituents during neointimal hyperplasia after vascular injury: potential contribution of bone marrow derived progenitors to arterial remodeling. Cardiovasc Pathol. 2004;13:306-312.

19) Kubota N, Terauchi Y, Kubota $\mathrm{T}$, et al. Pioglitazone ameliorates insulin resistance and diabetes by both adiponectin-dependent and -independent pathways. J Biol Chem. 2006;281:8748-8755.

20) Okamoto Y, Kihara S, Ouchi N, et al. Adiponectin reduces atherosclerosis in apolipoprotein E-deficient mice. Circulation. 2002;106:2767-2770.

21) Braun M, Pietsch P, Schror K, et al. Cellular adhesion molecules on vascular smooth muscle cells. Cardiovasc Res. 1999:41;395-401.

22) Ishikawa $\mathrm{Y}$, Akasaka $\mathrm{Y}$, Ishii $\mathrm{T}$, et al. Changes in the distribution pattern of gelatin-binding protein of $28 \mathrm{kDa}$ (adiponectin) in myocardial remodelling after ischaemic injury. Histopathology. 2003;42:43-52.

23) Kojima S, Funahashi T, Sakamoto T, et al. The variation of plasma concentrations of a novel, adipocyte derived protein, adiponectin, in patients with acute myocardial infarction. Heart. 2003;89:667-668.

24) Yoda-Murakami M, Taniguchi M, Takahashi K, et al. Change in expression of GBP28/adiponectin in carbon tetrachloride-administrated mouse liver. Biochem Biophys Res Commun. 2001;285:372-377.

25) Negoro T, Shimizu S, Narushima M, et al. Elevated receptor for activated C kinase 1 expression is involved in intracellular $\mathrm{Ca}^{2+}$ influx and potentially associated with compromised regulatory $\mathrm{T}$ cell function in patients with asthma. Clin Exp Allergy. 2014;44:1154-1169.

26) Martinez Cantarin MP, Waldman SA, Doria C, et al. The adipose tissue production of adiponectin is increased in end-stage renal disease. Kidney Int. 2013;83:487-494.

27) Van Berendoncks AM, Garnier A, Beckers P, et al. Functional adiponectin resistance at the level of the skeletal muscle in mild to moderate chronic heart failure. Circ Heart Fail. 2010;3:185-194.

28) Komura N, Maeda N, Mori $\mathrm{T}$, et al. Adiponectin protein exists in aortic endothelial cells. PLoS One (Internet). 2013;8:e71271. (accessed 2014 Jan 29) Available from:http://journals.plos.org/plosone/article?id =10.1371/journal. pone.0071271

29) Zhang W, Shu C, Li Q. et al. Adiponectin affects vascular smooth muscle cell proliferation and apoptosis through modulation of the mitofusin-2-mediated Ras-Raf-Erk1/2 signaling pathway. Mol Med Reports. 2015:12;4703-4707.

30) Jortay J, Senou M, Delaigle A, et al. Local induction of adiponectin reduces lipopolysaccharide-triggered skeletal muscle damage. Endocrinology. 2010;151:4840-4851.

[Received November 24, 2016 : Accepted January 11, 2017] 